\title{
Human behaviours: new paradigms of energy efficiency. Communication tools to deliver a technical message to non-experts
}

\author{
Benedetta Gaglioppa ${ }^{1, *}$, and Federica Tabone ${ }^{2}$ \\ ${ }^{1}$ Free-lance Professional, Trambileno (TN), IT \\ ${ }^{2}$ Free-lance Professional, Nove (VI), IT
}

\begin{abstract}
In the application of new technologies and incentive model, the complexity of the decision-making process requires new attention. Human behaviour increasingly influences the success of the implementation of technologies for energy saving and comfort, from the decision-making phase to the use of the building, including operation and maintenance activities. A new approach can help people understand, participate, be involved, and maximize the results of a complex operation that directly involves them. Communication and the development of behaviour change programs have many advantages: they are savings measures with an excellent cost-benefit ratio, which can trigger virtuous behaviours thanks to access to emotions that move the limbic part of the human brain, such as fear failure, the desire to excel or immediate success, the promise of a reward, etc. This paper provides an overview of the concepts and behavioural change initiatives that can be most effective in saving energy. A brief on effective communication will be provided, then the project of an awareness campaign in condominiums will be described, followed by a focus on the tool of graphic recording and graphic facilitation that can be used effectively to arise people awareness and conduct an audience to take decision. The paper itself will be presented as an application of this and will use the graphic recording technique to help conference participants to follow and remember the concepts. In a liquid society, soft skills and technical skills are both fundamental and this awareness is only the beginning of a new approach to conduct complex projects with satisfying results for all stakeholders. Key words: energy savings, rational energy use, sustainable energy development, human behaviour, effective communication.
\end{abstract}

\section{Introduction}

In contemporary societies, faced with an ecological conscience that has firmly become part of the mass narrative and with huge investments in the field of technological innovation, significant difficulties are observed in strategically orienting in-dividual motivations and behaviours, and in promoting their sedimentation in daily practices that

\footnotetext{
*Corresponding author: bgaglioppa@gmail.com
} 
have a lasting and measurable impact on the production and consumption model. An indepth study of the cultural and psycho-social dimensions of environmental sustainability has therefore become an urgent need. The study carried out by Inghileri et al. [1] shows how research on cultural, social, and individual dimensions is still in its infancy and in many sectors and countries it has not yet been conducted in a systematic way and involving enough the more social and psychological disciplines.

These difficulties also underline the need for a conceptual re-framing of the problem. Its representation by social groups, research bodies and policy makers tend, in fact, to focus mainly on the contribution of the STEM sciences (Science, Technology, Engineering and Mathematics), neglecting its eminently cultural and behavioural nature. In the words of Winter and Koger [2]:

"Entrusting the future to physical scientists and their technicians misses the primary cause of the current predicament and a crucial strategy for lasting solutions: changing human behaviour. It is critical to examine the psychological dimensions of planetary difficulties because "environmental problems" are behavioural problems: they are caused by the thoughts, beliefs, values, and worldviews upon which human beings act."

In the complexity of the current situation, the issue of energy behaviours in the home and the involvement of people in decision-making processes take on enormous importance; an example of this is the condominium administrator who would like to promote the adoption of virtuous energy behaviour and take the opportunity to redevelop his buildings by accessing the recently introduced incentives.

The psychological and social aspects are fundamental in this process, but not easy to measure and manage, and require the introduction of soft skills and new professional figures in the decision-making process that can constitute a bridge be-tween the human and technical aspects.

Although not the subject of this paper, the reasoning model proposed by Inghileri et al. [1] is reported; the following figure shows the complexity of aspects that influence human behaviour, not always in a conscious way. The daily life of personal choices is moved more or less consciously by distal parameters, such as cultural or group belonging, and proximal parameters, summarized as motivations and attitudes. Being able to understand and manage these aspects has become increasingly important even in situations that until yesterday seemed to be attributable to the purely technical sphere. 


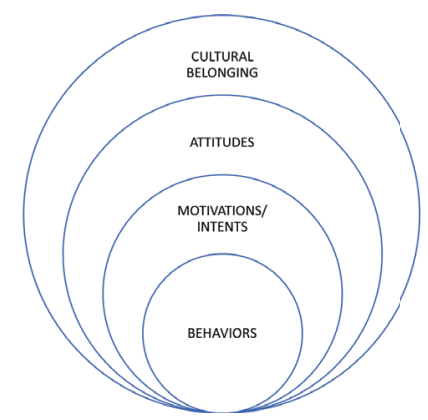

Fig. 1. Systemic modelling of behaviours from a psycho-social perspective. From Inghileri et al. [1].

\section{The European and Italian context}

From an international research [3] also reported in Inghileri et al. [1], the level of Future Orientation, hereinafter referred to as FO, has been com-pared with a sustainable behaviour index, consisting of questions regarding both the private sphere of behaviour (domestic recycling, reuse, energy consumption, purchase of organic products, use of the car) and the public propensity for activism for sustainability in 21 different nations.

A strong correlation emerged between the orientation to the future and the declared behaviours, present in all the nations considered. According to the authors, this correlation can be explained by considering sustainable behaviours as a subset of a larger group of forward-looking behaviours that are more common in some countries than others. These nations (Switzerland, the Netherlands, Canada, Den-mark) are therefore characterized by the ability of their inhabitants to favour a medium-long term vision over the immediate gratification of needs, which is instead predominant in the imagination and in the public discourse of countries, such as Russia, Spain, Portugal. Not surprisingly, the FO indices also appear to be correlated with national trends in collectivism and the avoidance of uncertainty.

In Italy, most of the developed research focuses on energy efficiency and top-down initiatives aimed at improving sustainability. The researches are carried out in the technicalengineering field, without adequately considering the psycho-social aspect.

In summary, from the few social studies carried out, the following information is highlighted by Inghileri et al. [1]:

a) Substantial contradiction of the Italian situation, characterized on the one hand by attitudes close to those that characterize "advanced" countries in the field of sustainability (high perception of the risks of climate change, long-term orientation, trust in collective action, broad diffusion of some sustainability practices), on the other by indicators of opposite sign (individualism, low perception of individual responsibility, refusal to disincentive policies, poorly developed diffusion of some pro-environmental behaviours).

b) This contradiction presents, as a psychological corollary, a widespread phenomenon of dissonance between attitudes and behaviours, where a partial dis-investment of individual responsibility is observed in the face of a request for se-verity addressed to the legislative system, in a representative framework of ecological problems such as "problems of the production system", to be solved without requiring citizens to make significant 
changes in their personal habits and behaviours, in particular as regards the use of fossil fuels.

c) The differences on a territorial scale (geographical, economic, climatic) are so significant as to recommend the adoption of differentiated intervention methods in the different territories. In particular, the following variables of distinction within the population are highlighted:

- climate and meteorology;

- housing solutions (autonomous, small or large condominium);

- residence (urban, peri-urban, extra-urban / rural);

- age and gender;

- number of family members.

d) The imaginary relating to sustainable behaviour is articulated, in the Italian context, around two fundamental elements: economic savings / gain and the protection of health, threatened by the ongoing pollution processes.

In addition to the social context, it is important to recall here some demo-graphic and consumption data related to the condominium sector, to understand how an approach that includes social and psychological aspects is fundamental for the success of a process of improving the use of resources to be part of our buildings both from a technical and a social point of view.

In Italy, almost $40 \%$ of final energy consumption and over $36 \%$ of greenhouse gas emissions comes from buildings and three out of four buildings are not sufficiently efficient.

According to data of the Practical guide to the renovation and energy retrofit-ting of buildings [4] nationwide there are about 2 million condominiums that house 22 million people; in this context, the weight of the buildings built before the legislation on energy saving came into force in buildings with centralized heating and specific consumptions above $170 \mathrm{kWh} / \mathrm{m} 2$ year, is very significant, a figure that translates into climatic zone $\mathrm{E}$ for a apartment of about 80 square meters with a consumption of at least 1,400 m3 of natural gas at current fuel rates of over $€ 1,500$ per year.

According to "Household consumption expenses 2018" [5] in 2018 the average annual expenditure of families was $2571 € /$ month, of which $116 € /$ month to support the energy costs of the house $(57,13 € /$ month for gas and $49,83 € /$ month for electricity).

The energy consumption of a residential building depends on several factors. First is the climatic factor linked to the location; secondly, the composition of the family unit. These factors are important for analysing consumption, but they are not factors on which it is possible to intervene to implement energy efficiency measures. Two other factors that affect energy consumption are the consumption habits of the occupants and the energy quality of the building-plant system; these are the levers that can help reduce energy consumption, reducing waste and de-creasing the energy needed for a given goal.

In this paper, some action strategies on behavioural factors that influence energy efficiency will be explored, with particular focus on communication strategies. 


\section{Effective presentation}

The behavioural change and the involvement of people in energy efficiency objectives pose a highly topical issue: effective communication, to be considered not only in relation to the building users but also and above all in the context of communicating mainly technical topics.

Everyone needs to know how to communicate, and in the era of emotions, social and digital life this is always more important. In any profession there is the opportunity to meet and collaborate with new people, perhaps quite different from us, both in terms of skills and in terms of personality. Therefore, it is important to know how to communicate in an effective way: correct content is not enough, if this is not related to the capacity of transmitting it adequately to the listener. Improving communication skills, both professionally and personally, is possible through the effective use of a tool available to anyone: language.

An effective communication helps better interpersonal relationships, developing greater awareness and self-esteem, managing to avoid creating or suffering misunderstandings and managing conflict situations.

Knowing how to communicate helps to learn to listen: the search for a solution always starts from listening. The basis of good communication lies in learning to listen actively: listening to the words of those in front of you, but also observing and decoding their nonverbal reactions, their body language, the paraphernal aspects of communication. Above all, learning to listen means paying attention to understand and not listening to respond: it means entering a real relationship with the other, the only way to understand their requests, needs, preferences.

The main characteristics of effective communication are introduced in the next paragraphs.

\subsection{Concept of the talk}

The first phase is analysis and thought, typically takes place with pen and paper, it does not start from the slides but from the analysis of the objectives, the audience, the structure.

Once the objectives and the audience have been defined, the activity moves to the planning of the presentation, still understood not as the practical realization of the slides or the material chosen as support, but as:

- attention to the available spaces (online mode or physical meeting, arrangement of the furniture, the seats of the participants, online mode with or without webcam on);

- available tools (flip chart, remote control, projector);

- non-verbal communication (What is the ideal disposition to involve the audience? Will the speaker be standing or seated? Better to avoid, for example, speaking from behind the desk because this puts a barrier between the speaker and listeners).

\subsection{Time Management}

Statistics on a speech time management indicate as a rule that in a presentation of about one hour, the attention curve of an auditor reaches its peak after the first 7-8 minutes, then it has a constant decline until it reaches the minimum towards $26-27$ minutes of lessons. Finally, it goes back up, remaining fairly constant until the end of the hour, always below the initial apex. The figure below shows the attention curve. 


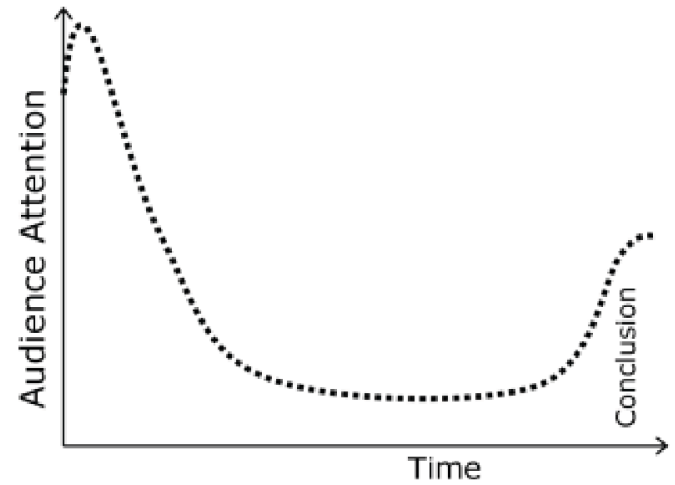

Fig. 2. Typical attention of the audience paid to an average presentation [6].

In organizing a lesson, therefore, each single topic should last no more than 20 minutes.

The speaker can organize the speech into sub-topics always summarized by conclusions to resume the concepts expressed and connect them to the next, providing moments of opinions exchange, questions and answers time that help to maintain attention and interest.

The figure below shows an ideal attention curve where the presentation con-siders the potential attention bias and is designed to engage the audience and keep the attention high at the most important points.

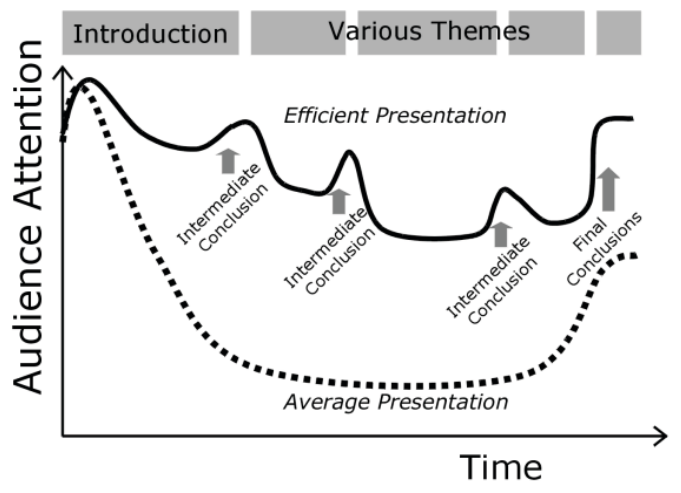

Fig. 3. Ideal attention curve [6].

The curve shows how the speaker can divide the speech into parts that the listener can follow, formulating sub-topics and related conclusions that maintain interest and attention.

\subsection{Actual Processing of the presentation material}

An effective presentation starts from the study of the audience, the objectives and all the factors that can influence its success. 
Once the initial study has been completed, the preparation for the exposure must consider some aspects.

First is the structure of the presentation, i.e., how the contents are organized in a certain sequence.

The right structure is not necessarily the most used one, but the one that helps to reach the goal and involve the public.

The description of the existing presentation structures is not the subject of this paper, but here it is interesting to indicate two of them to grasp the differences in the choice by the same kind of speaker based on the objectives.

The first one is the Hero's Journey, which is a narrative model created by Christopher Vogler [7], that helps structure and generate stories.

The narrative approach proposed can be a good tool in persuasive communication.

In some situations, such as condominium assemblies, the objective is to take decision and to define budget items. The technical issue is composed of lists, numbers, expense items, no stories. But if the decision has not been taken yet, the budget has not been approved yet and the audience is sceptical and perhaps does not have a common base of knowledge and beliefs, lists and numbers may not be enough.

With the story telling proposed by the Hero's Journey the decision-making phase is more likely to be successful. The Hero's Journey is described by twelve phases, where the story moves forward connecting the audience with the Hero and, at the same time, transferring the presentation message to the audience. The phases are described below:

1. Ordinary World: the journey begins with the presentation of the hero in his ordinary world. What are the kinds of problems he/she faces? What are the Hero's goals?

2. Call to Adventure: something happens to the Hero and the adventure starts.

3. Refusal: the hero is reluctant and refuses the call and usually the audience also shares in these emotions.

4. Meeting a Mentor: the hero receives encouragement from a Mentor gives the message that the problem can be solved.

5. Crossing the Threshold: the hero accepts the challenge and crosses the threshold towards adventure (departure).

6. Tests, Allies, Enemies: throughout his/her adventure the Hero encounters both positive and negative forces, such as allies and enemies to meet.

7.Approach: the hero arrives in an extremely hostile place and is forced into trying a new approach or idea.

8. Ordeal: the Hero is challenged with an obstacle. This marks another crucial moment in the story, where a transformation takes place.

9. Reward: after overcoming the obstacle, the Hero achieves their goal celebrates, also because he has learned.

10. Road Back: the hero returns to his world, now better.

11. Resurrection: the Hero faces a final challenge before returning to their everyday life. This creates an opportunity to test and apply what he/she has learned.

12. Return: the Hero returns to the ordinary world. This allows the audience to understand the meaning of the journey and brings a sense of completion to the story.

This structure works very well in front of audiences where there is no need to go into detail about a project, but the aim is to involve the public on a topic. 
A presentation with this structure moves between reality, what it is, and the future enhanced by the proposed idea. The strength of this structure is that resistance to change must be anticipated in the design phase and can be used as an advantage to move forward and build a better future together with the public.

The second structure that is helpful to present in this paper is the Pyramid structure. This type of structure works very well for those preparing business presentations. The Minto Pyramid Principle ${ }^{\circledR}$, theorized in 1967 by Barbara Minto [8], is the official method for giving logical structure and strategic orientation to communication. Figure 4 represents a diagram of Pyramid structure; it is based on three key principles:

1. Start with the answer first; then argue with details. The strength of this structure is to go straight to the resolution of the problem.

2. Group and summarize the support topics. Divide the answer to the problem into more specific ideas and topics so that they hold up the key idea, just like a pyramid. A very broad and solid base supports a very sharp tip.

3. Logically order the support ideas. There are various orders that can be used:

a) temporal order: explanation of the relationship between cause and effect, it and works vertically;

b) structural order: break a topic down into its parts, ensuring that all major supporting ideas have been covered;

c) hierarchical order: presents the supporting ideas from most to least important.

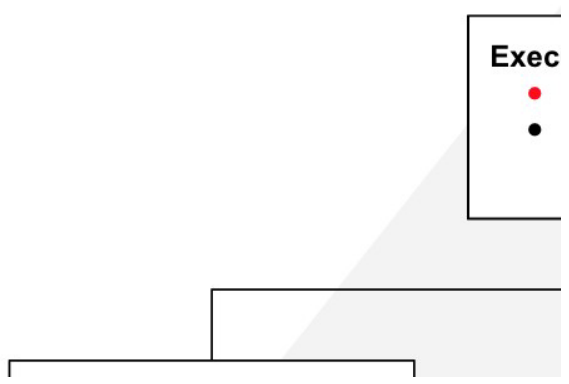

Fig. 4. Schematics of the Pyramid of Minto. From Medium.com.

The advantage of a pyramid structure is that the focus of the solution is revealed at the beginning of the speech, when attention is high and when most of the audience is present; it is not uncommon for business presentations, the decision makers who should listen to the conclusions of the presentations may need to be absent in advance.

\subsection{Presentation Delivery}

Presenting something is more than just acting out facts. It is a real performance including theatrical and dramatic elements. The presenter should learn to communicate effectively using not only words but also body language, the right rhythm, emotions, 
awareness of the audience and how these elements affect them. Each presentation is a performance aimed at entertaining the audience so that at the end they are enriched (possibly with what they expected, better if more).

Entertaining always trumps informative.

Punctuality and preparation are good prerequisites for a successful presentation.

\section{Effective communication for energy saving in condominiums}

Starting from the evidence identified so far, in this chapter the authors try to outline a path for the design and implementation of an awareness campaign aimed at residents in condominium buildings. The goal is to intervene on these subjects to push them to reduce their consumption by eliminating waste, to promote the implementation of first 'zero cost' interventions to favour the dialogue towards the approach to energy retrofitting.

To achieve this result, avoiding individual action, it is vital to involve the en-tire condominium community. Through effective engagement and consultation, the administrator must be sure to obtain a good understanding of the processes in-volved, the opportunities and potential challenges specific to the building's energy retrofitting.

This will help facilitate an informed discussion of potential improvements and help the condominium identify what will help or, conversely, hinder decision making.

In the Practical guide to the renovation and energy retrofitting of buildings [4] an outline of the communication plan is reported. The plan highlights the main phases, the necessary resources, and some suggestions for the success of the process.

The phases are briefly described below with some specific insights and examples of application in real cases.

\section{Phase 1 - Planning}

Planning is fundamental in all projects that involve multiple stakeholders; when it comes to raising awareness of an audience on a subject not known or shared by all, it is essential to plan the activities well in order not to frustrate the efforts for an oversight in terms of communication. In the planning phase the main points are:

- support and resources;

- the current situation;

- the target and the setting of objectives;

- communication channels and messages.

Phase 2 - Implementation

An important aspect to consider is when to start the campaign so that most condominiums can be involved; the campaign should also last long enough for it to be effective. From an organizational point of view, promotional materials and the support of people who can help the condominium administrator and the facilitator to spread the word are also useful.

Phase 3 - Review and communication

The awareness campaign is not a training moment, but a path. It is like implementing an energy communication system in a community (the condominium). It is therefore important that there are moments of review and adjustment of the campaign management methods to know people's feedback. 


\section{Phase 4 - Permanence of awareness}

As in an energy management system, the awareness campaign should focus on permanence in the audience.

New condominiums should be informed of the process; the involvement of new participants could also be the possibility to enhance cooperation and interest.

Maintaining interest is also important in the assembly that already participates in the project. Communications must be kept up to date, the topic of energy saving should be considered with each new purchase of energy-consuming equipment; it could be interesting to organize moments of aggregation with an energy theme, per-haps using common spaces and proposing sustainable and interesting activities (common garden, film screening, etc.)

\section{Phase 5 - Campaign materials and tools}

As early as in phase 1, the awareness campaign requires a budget, even for in-formation materials.

Communication tools can be of various types and therefore of various budgets. Here are some ideas:

- informative newsletters;

- playbills and posters;

- reminder stickers;

- word of mouth;

- sweepstakes or gamification;

- presentation and training meetings;

- advertising;

- post box for collecting feedback.

\section{Graphic facilitation for audience involvement}

This chapter explores a communication technique that can be effective to use as part of an awareness campaign on energy consumption in a context like that of the condominium: the graphic facilitation and recording.

As defined by Sibbet in "A graphic Facilitation Retrospective" [9], graphic facilitation is an interactive style of leading groups using large-scale imagery and displays". The method is used in various processes such as meetings, seminars, workshops, and conferences. The visual process is conducted by a graphic facilitator.

The application of this technique relies on the fact that a shared picture can support group learning and can last more in the group's memory.

Graphic recorders and facilitators combine the skills of a note-taker and an artist to visually represent information communicated orally. These two figures are similar, they might look the same but have a different function.

A graphic recorder has the goal to leave visual capture of content discussed or presented during an event. During the event, the charts tend to have more illustrations than in facilitating session because it is the focus. 
A graphic facilitator is mode involved with the client and with the event because he captures the key points and works with the audience and the team in the design process and facilitates the event. The charts are prepared before, as templates to fill during the meeting.

Capturing ideas through the technique of graphic facilitation and graphic re-cording offers a powerful tool for visualizing and implementing change at the individual, team, or organizational level. This technique is starting to be used to facilitate the decision-making process during the condominium meetings, where the dispersion of information and reduced attention makes the process lose its effective-ness.

The following four figure are taken from two condominium meetings where graphic facilitation and recording are being applied.

In the first meetings, the visual approach helps to create common and shared knowledge, to clarify and to keep attention where it is needed.

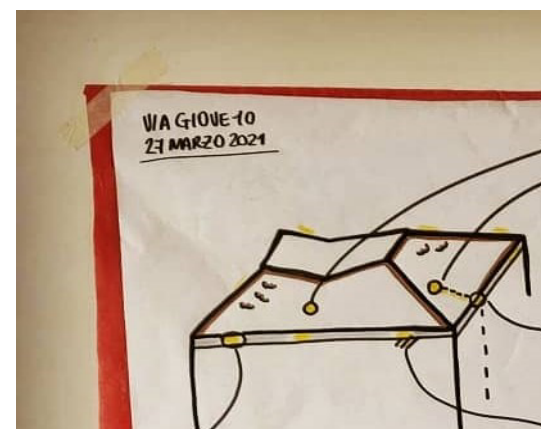

Fig. 5. Graphic recording - Condominium meeting 1.a. From Federica Tabone.

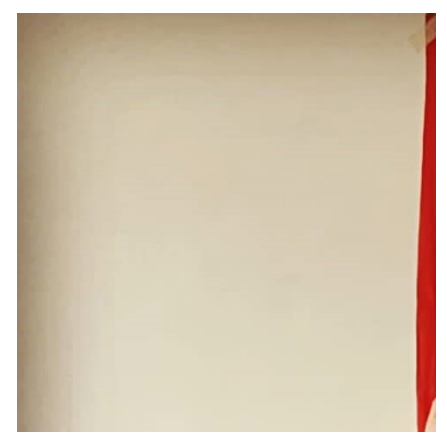

Fig. 6. Graphic recording - Condominium meeting 1.b. From Federica Tabone.

In the following meetings, where the topics are more related to problems, solutions and decisions, the challenge is how to translate the estimates in a visual way to facilitate the understanding of the costs and benefits of each intervention without having quantities of sheets and numbers that make the assembly uneasy. 
After the visual analysis, the assembly achieved the following results:

- the theme was shared;

- the simplified language helped to read the data and estimates;

- in a simple way it was possible to compare the solutions and the related costs.

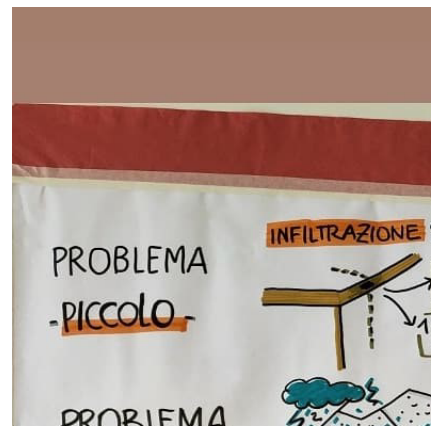

Fig. 7. Graphic recording - Condominium meeting 2.a. From Federica Tabone.

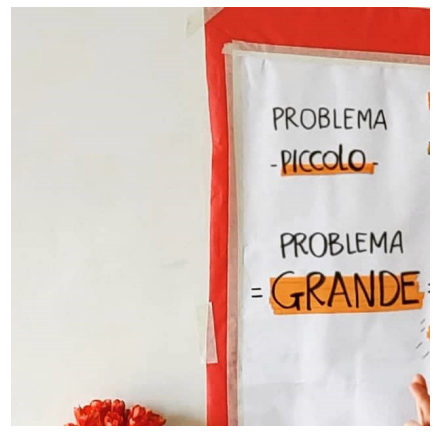

Fig. 8. Graphic recording - Condominium meeting 2.b. From Federica Tabone.

\section{Conclusions}

In this paper the topic of the importance of effective communication and of behaviour change program for energy saving awareness and renovation has been discussed.

In the complexity of decision-making process human behaviour management influences audience and their mood and decisions.

Even if the importance of this topic is increasingly shared and recognized, there are still not enough structured researches and studies that deal with the topic from a psycho-social as well as a technical point of view.

In this paper some communication and audience engagement tools have been shown, with reference and example to the condominium.

As a general outcome, the following general strategies can be recommended: 
- Positively promoting the economic value of individual behavioural choices and promoting behaviour for which it is easy to offer feed-back immediately.

- Increase in training and communication initiatives, starting from youth population to orient the habits towards positive behaviours.

- Promoting energy awareness and positive domestic behaviour on the correct use of heating systems and electrical appliances and heating.

- Implementation of communication tools to involve the audience in the decisionmaking process for energy management and renovation.

\section{References}

1. P. Inghileri, M. Boffi, L. Pola, N. Rainisio. I comportamenti energetici in ambito domestico. Dimensioni culturali, sociali ed individuali. Agenzia Nazionale Efficienza Energetica - ENEA (2020)

2. D. D. N. Winter, S. M. Koger. The psychology of environmental problems: Psychology for sustainability. Psychology Press, London. (2014)

3. N. Carmi, \& S. Arnon. The role of future orientation in environmental behavior: Analyzing the relationship on the individual and cultural levels. Society \& Natural Resources, 27(12), 1304-1320. (2014)

4. A. Boriani, W. Cariani, R. Romani. Guida pratica alla ristrutturazione $e$ riqualificazione energetica degli edifici per Amministratori di Condominio. Agenzia Nazionale Efficienza Energetica - ENEA (2020)

5. ISTAT. Household consumption expenses 2018. (2019)

6. Scientific Leaders Blog. www.scientificleaders.com. (2021)

7. C. Vogler. The Writer's Journey. (2007)

8. B. Minto. The Minto Pyramid Principle. (1967)

9. D. Sibbet. A Graphic Facilitation Retrospective. (2009) 